\title{
Scenario simulation and landscape pattern dynamic changes of land use in the Poverty Belt around Beijing and Tianjin: A case study of Zhangjiakou city, Hebei Province
}

\author{
SUN Piling ${ }^{1},{ }^{\text {XXU Yueqing }}{ }^{1}$, YU Zhonglei ${ }^{2}$, LIU Qingguo ${ }^{3}$, XIE Baopeng ${ }^{1}$, LIU Jia ${ }^{1}$ \\ 1. College of Resource and Environmental Sciences, China Agricultural University, Beijing 100193, China; \\ 2. School of Geography, Beijing Normal University, Beijing 100875, China; \\ 3. Qianjiang Xinhua Middle School, Chongqing 409000, China
}

\begin{abstract}
Land use/cover change has been recognized as a key component in global change and has attracted increasing attention in recent decades. Scenario simulation of land use change is an important issue in the study of land use/cover change, and plays a key role in land use prediction and policy decision. Based on the remote sensing data of Landsat TM images in 1989, 2000 and 2010, scenario simulation and landscape pattern analysis of land use change driven by socio-economic development and ecological protection policies were reported in Zhangjiakou city, a representative area of the Poverty Belt around Beijing and Tianjin. Using a CLUE-S model, along with socio-economic and geographic data, the land use simulation of four scenarios-namely, land use planning scenario, natural development scenario, ecological-oriented scenario and farmland protection scenario-were explored according to the actual conditions of Zhangjiakou city, and the landscape pattern characteristics under different land use scenarios were analyzed. The results revealed the following: (1) Farmland, grassland, water body and unused land decreased significantly during 1989-2010, with a decrease of $11.09 \%, 2.82 \%, 18.20 \%$ and $31.27 \%$, respectively, while garden land, forestland and construction land increased over the same period, with an increase of $5.71 \%$, $20.91 \%$ and $38.54 \%$, respectively. The change rate and intensity of land use improved in general from 1989 to 2010 . The integrated dynamic degree of land use increased from $2.21 \%$ during $1989-2000$ to $3.96 \%$ during $2000-2010$. (2) Land use changed significantly throughout 1989-2010. The total area that underwent land use change was $4759.14 \mathrm{~km}^{2}$, accounting for $12.53 \%$ of the study area. Land use transformation was characterized by grassland to forestland, and by farmland to forestland and grassland. (3) Under the land use planning scenario, farmland, grassland, water body and unused land shrank significantly, while garden land, forestland and construction land increased. Under the natural development scenario, construction land and forestland increased in 2020 compared with 2010, while farmland and unused land decreased. Under the ecological-oriented scenario, forestland increased dra-
\end{abstract}

Received: 2015-04-15 Accepted: 2015-10-12

Foundation: National Natural Science Foundation of China, No.41171088, No.41571087

Author: Sun Piling (1984-), PhD Candidate, specialized in land use/cover change, sustainable utilization of land resources. E-mail: sapphire816@163.com

"Corresponding author: Xu Yueqing (1972-), PhD and Associate Professor, E-mail: xmoonq@sina.com 
matically, which mainly derived from farmland, grassland and unused land. Under the farmland protection scenario, farmland was well protected and stable, while construction land expansion was restricted. (4) The landscape patterns of the four scenarios in 2020, compared with those in 2010 , were more reasonable. Under the land use planning scenario, the landscape pattern tended to be more optimized. The landscape became less fragmented and heterogeneous with the natural development scenarios. However, under the ecological-oriented scenario and farmland protection scenario, landscape was characterized by fragmentation, and spatial heterogeneity of landscape was significant. Spatial differences in landscape patterns in Zhangjiakou city also existed. (5) The spatial distribution of land use could be explained, to a large extent, by the driving factors, and the simulation results tallied with the local situations, which provided useful information for decision-makers and planners to take appropriate land management measures in the area. The application of the combined Markov model, CLUE-S model and landscape metrics in Zhangjiakou city suggests that this methodology has the capacity to reflect the complex changes in land use at a scale of 300 $\mathrm{m} \times 300 \mathrm{~m}$ and can serve as a useful tool for analyzing complex land use driving factors.

Keywords: land use change; Markov model; CLUE-S model; landscape metrics; Zhangjiakou city

\section{Introduction}

Land use changes result from the interaction between humans and nature (Vitousek et al., 1997; Liao et al., 2011) and involve complex mechanisms and processes (Sohl and Claggett, 2013). Land use and land cover change (LUCC) is a complex process subject to the interactions between natural and social systems on different temporo-spatial scales (Veldkamp and Lambin, 2001). It is a principal component, and main cause, of global environmental changes, and it has emerged recently as an important focus in the study of land use change. At present, the study of LUCC and its effects has increasingly become a core element of global environmental change and sustainable development research (Feng et al., 2013; Xu et al., 2011; Xu et al., 2013b). Increasing attention has been paid to the driving factors involved in such processes, and the effects of LUCC. The simulation of global and regional land use changes has been employed as a new method for studying LUCC (Liu et al., 2002; Couclelis, 2005). Models and scenario analysis are useful tools for understanding land use patterns and the complex mechanisms of socio-economic and physical variables that influence land use change, and have been recognized as excellent tools for simulating land use changes (Li et al., 2001; Britz et al., 2011; Deng et al., 2013). Currently, different approaches and models have been widely used in many researches on LUCC and have yielded good results (Evans et al., 2001; Tang et al., 2009; Zhang et al., 2014b). Some models, especially dynamic models, can support decision makers in simulating future scenarios. For instance, Markov chains, system dynamics (SD) models, cellular automata (CA) models, multi-agent system (MAS) models, and the Conversion of Land Use and its Effects at Small regional extent (CLUE-S) model have frequently been applied to the simulation of spatio-temporal land use changes (Hu et al., 2013; Liang et al., 2011; Ou et al., 2014; Chen et al., 2009; Tian and Ren, 2012; Zeng et al., 2014; Wu et al., 2014). The CLUE-S model has been considered as an excellent tool for simulating land use changes. It can be used to explore the competition between different types of land uses based on systems theory, to simulate different land uses simultaneously, and to produce a spatially explicit display of the simulation results (Overmars and Verburg, 2007; Hu et al., 2013). Recently, the CLUE-S 
model has been used to simulate land use change in certain hot spots, such as plateau cities, mining cities, Heihe River basin, Huangshui River basin, Luoyugou watershed, metropolitan fringe areas, loess hilly areas, and the Danjiangkou reservoir area (Zhang et al., 2013a; Dai and Zhang, 2013; Feng et al., 2013; Huang et al., 2012; Deng et al., 2013; Li et al., 2011b). In terms of hot spots, it is necessary to pay more attention to the ecologically fragile areas, where land use changes remarkably. Analyzing land use changes with the CLUE-S model in such areas makes a significant contribution to the research into global change.

Land use is a direct indicator of human interaction with the landscape. Land use cover may be defined as the primary landscape on the earth's surface influenced by both human activities and natural conditions. Landscape patterns may be defined as the quantitative description of the spatial composition and configuration of land use, which have both spatial and temporal characteristics. Landscape pattern indexes are proposed to quantitatively describe landscape patterns. Currently, many researches on landscape patterns are focused on analyzing landscape pattern changes in land use. However, landscape pattern indices have not been included in land use change models (Yang et al., 2014).

Recently, remote sensing (RS) and geographical information system (GIS) have often been combined to assess land use change effectively. RS integrated with GIS provides an excellent framework for data capture, storage, processing and analysis (Wang et al., 2010). In order to analyze land use changes systematically, landscape metrics have been integrated into LUCC models such as the CLUE-S model, Markov-CA (cellular automata) model, Markov-CLUE-S model and SD (system dynamics)-CLUE-S model (Zeng et al., 2014; Wang et al., 2014; Hu and Dong, 2013; Zhang et al., 2014b; Hu et al., 2013; Luo et al., 2010; Zheng et al., 2015). These methods have proved useful in the analysis and prediction of land use changes. The Markov-CA and CLUE-S models integrate landscape pattern indices (LPIs) to accomplish the simulation of land use dynamics, which can provide scientific bases for land use planning and management.

The Poverty Belt around Beijing and Tianjin, located in the north of Hebei Province, bordering with Beijing and Tianjin city, is a typical ecologically fragile area and comprises 31 administrative districts. This belt involves the whole of Chengde city and Zhangjiakou city, and part of Baoding city. Owing to the harsh natural environment, population pressure, and unreasonable human activities such as over logging and steep-slope farming, the Poverty Belt has been experiencing serious soil erosion, desertification of land, natural disasters and environmental deterioration, resulting in a vicious cycle of poverty. With the initiation of the integrated and coordinated development of the Beijing-Tianjin-Hebei region, the society and economy in the Poverty Belt will develop rapidly. The competition for land use among different industries and departments will intensify, and the contradiction between land supply and demand will become more marked. Although there have been many researches into the causes of, and solution to, the poverty of the Poverty Belt around Beijing and Tianjin, most of these have focused on development strategies and patterns relating to the regional economy, ecological compensation mechanisms, environmental deterioration, and the effects of land use changes (Sun et al., 2014). Few researches on land use changes using LUCC models and scenario analysis have been conducted in relation to the Poverty Belt around Beijing and Tianjin. The main problems of this area are closely associated with land use changes, so the effective analysis and simulation of land use changes is critical to 
rectifying many of the problems relating to the eco-environmental management of the Poverty Belt. There is an urgent need to simulate land use change scenarios driven by socio-economic and ecological protection policies to ensure sustainable land use planning and management in this particularly fragile and poverty-stricken environment.

The principal aims of this study were: (1) to propose an integrated model based on the Markov-CLUE-S model and LPIs; (2) to describe the temporal and spatial characteristics of land use change and identify the primary driving factors; and (3) to predict and simulate the evolution of land use patterns and landscape characteristics under different scenarios.

\title{
2 Study area
}

Zhangiiakou city, located in the northwest of Hebei Province, is a main part of the Poverty Belt and plays a key role in water conservation and ecological security for Hebei and Beijing. The region's latitude ranges from $39^{\circ} 30^{\prime}$ to $42^{\circ} 10^{\prime} \mathrm{N}$, while its longitude ranges from $113^{\circ} 50^{\prime}$ to $116^{\circ} 30^{\prime}$ E. It covers an area of $3.68 \times 10^{4} \mathrm{~km}^{2}$ (Figure 1), which includes 13 counties (Kangbao, Zhangbei, Guyuan, Shangyi, Huai'an, Wanquan, Xuanhua, Yuxian, Yangyuan, Zhuolu, Huailai, Chongli and Chicheng) and 4 districts (Qiaoxi, Qiaodong, Xuanhua and Xiahuayuan). Its elevation ranges from $320 \mathrm{~m}$ to $2841 \mathrm{~m}$ above sea level. The study area is located in the transition zone of the North China Plain and the Inner Mongolia Plateau, with elevations increasing from southeast to northwest. Zhangjiakou city is one of the most important areas for conserving water and providing an ecological defense for Beijing and Tianjin. Moreover, it is also a typical mountainous region with ecosystem vulnerability and sensitivity. It is characterized by a typical temperate continental monsoon climate. The mean annual precipitation is about $350 \mathrm{~mm}$ and the annual average temperature is $7.8^{\circ} \mathrm{C}$, both of which have clear seasonal variations. However, with the growth in population and economic activities, land use in the study area has changed dramatically over the past two decades. The ongoing land use change shows obvious spatial differentiation characteristics. There is higher terrain in Bashang Plateau with a significantly undulating plateau landscape. While the landscape under the dam is characterized by hills and mountains, which has changed

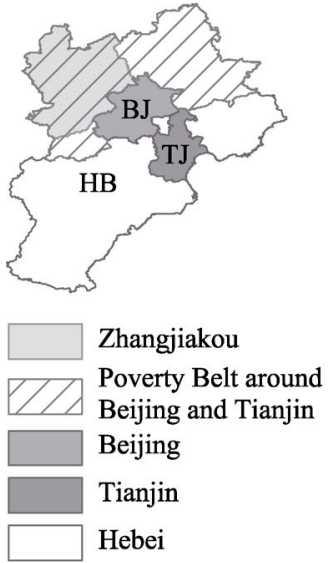

1. Qiaoxi District 2. Qiaodong District 3. Xuanhua District 5. Huailai County 6. Xuanhua County

- River

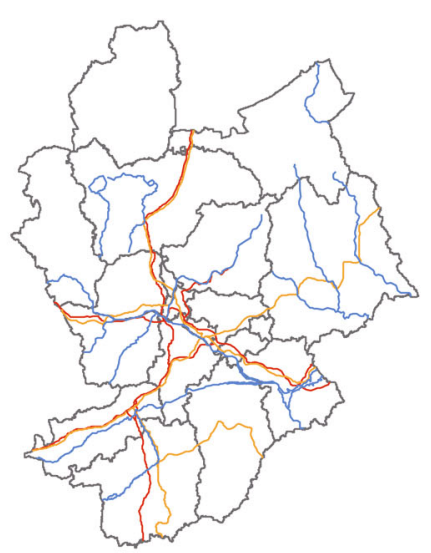

4. Xiahuayuan District 8. Shangyi County County boundary

Highway

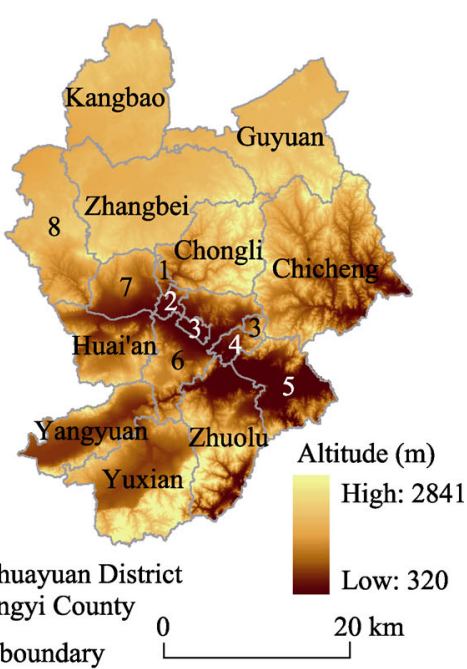

\begin{abstract}
County boundary
\end{abstract}
Figure 1 Location of the study area and its elevation 
dramatically with complex terrain, Zhangjiakou has undergone rapid urbanization and economic growth since the economic reforms of 1995, and by 2010 the total population of the city had reached 4.35 million according to China's sixth population census. With per-capita grain output up to $315 \mathrm{~kg}$, the city's per-capita net income for farmers was 4119 yuan RMB, and its GDP was approximately 966.42 billion yuan then. Therefore, Zhangjiakou city is a typical representative of the Poverty Belt around Beijing and Tianjin.

\section{Data and methods}

\subsection{Data sources and processing}

The data used in this study comprised: (1) remote sensing (RS) data, including Landsat Thematic Mapper (TM) data images for 1989, 2000 and 2010; (2) data for soil organic matter (at a resolution of $100 \mathrm{~m}$ ), derived from the Institute of Remote Sensing Applications, Chinese Academy of Sciences; (3) terrain data, supplied by the national digital geomorphic database at a 1:1,000,000 scale and the geospatial data cloud information platform (http://www. gscloud.cn/; accessed November 2015); (4) socio-economic data, derived from annual statistics of Zhangjiakou city and rural annual statistics of Hebei Province; and (5) road data (i.e., highways, railways, state roads) and river data, derived from the present land use map of Zhangjiakou city at a scale of 1:10,000.

The processing procedure for the source data was as follows: (1) Subjects for land use were determined from the original data. The data for land use cover was derived from historical TM data images by means of a user-computer interactive interpretation method and by conducting a field survey to check selected points in the field and on maps (Li et al., 2006). Following geometrical image correction and geo-referencing, the average location errors were estimated at less than $30 \mathrm{~m}$ (about one pixel). Global accuracies of $86.82 \%$, $88.92 \%$ and $90.46 \%$ were obtained for the 1989,2000 and 2010 images, respectively. The Kappa coefficients were $0.84,0.87$ and 0.88 , respectively for the same years. This accuracy met the recommended value (Ellis et al., 2010), so the data was available for further study (Zhang et al., 2013b). Based on the classification system reference to the national resources and environmental background dynamic remote sensing survey database, these land use maps of 1989, 2000 and 2010 were classified into eight land use types: farmland, garden land, forest land, grassland, residential and industrial land, transportation land, water body and unused land (Gong et al., 2009). Simultaneously, considering the requirement for the CLUE-S model, the proportion of land use type must be over 1\% of the total area (Zhang et al., 2013a). Residential and industrial land and transportation land are classified as construction land. As a result, we chose farmland, garden land, forest land, grassland, construction land, water body and unused land as data sources for the CLUE-S model (Figure 2). Furthermore, ESRI ArcGIS 9.3 was used for the spatial analysis. Topographic maps were collected for establishing the digital elevation model (DEM) to obtain other data (i.e, slope, aspect) and also had a spatial resolution. (2) For the unification of the geo-reference of subjects, we used the Gauss Kruger (GK) projection coordinates with original longitude $117^{\circ} \mathrm{E}$, original latitude $0^{\circ} \mathrm{N}$, Xi' an geodetic datum and Krassovsky ellipsoid. (3) For the rasterization of the vector data, a one-sample Kolmogorov-Smirnov (KS) test was initially used to test the socio-economic data. The results showed that the asymptotic significance level was 
above 0.05 . They indicated that the population and per-capita net income of the farmers followed a normal distribution, and that other socio-economic data approximated to a normal distribution by $\log$ transformation. Therefore, the spatial distribution of socio-economic data could be obtained by spatial interpolation using the Kriging and natural neighbor methods. According to the requirements of the CLUE-S model combined with the actual location of Zhangjiakou city, many types of data layers were transferred to a grid format with a resolution of $300 \mathrm{~m} \times 300 \mathrm{~m}$ using the same projection coordinates, on which spatial logic and algebraic computations were calculated at each subject layer. Finally, all variables were normalized to allow a uniform measurement system (Locantore et al., 2004).

(a) 1989
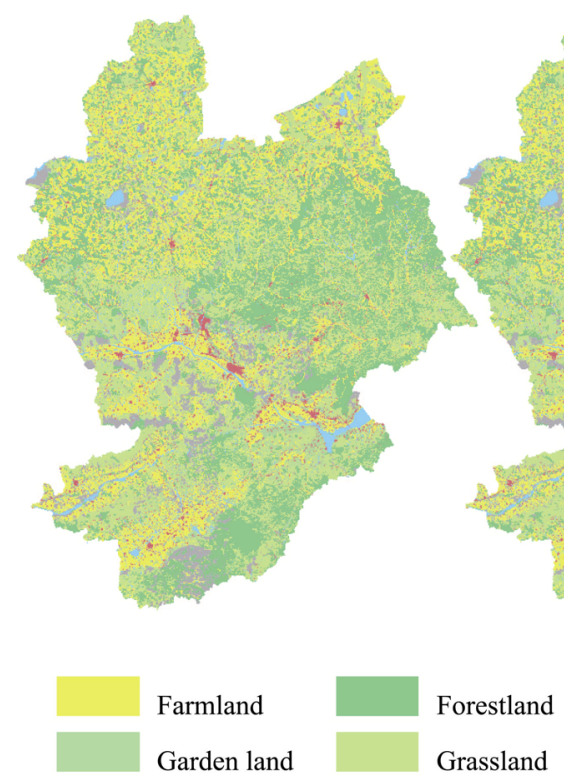

(b) 2000
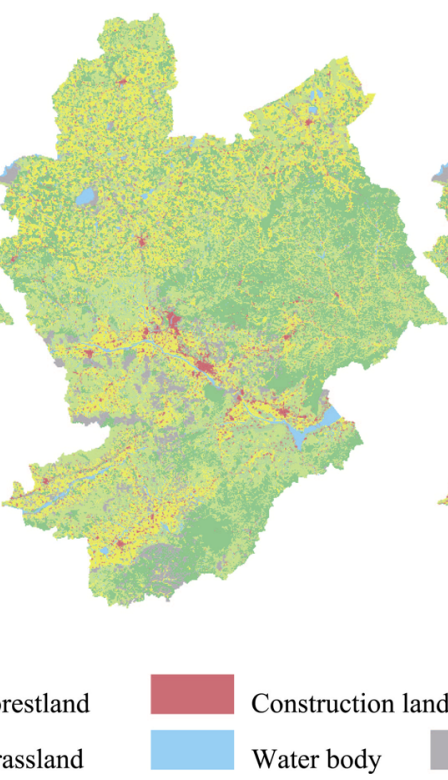

(c) 2010

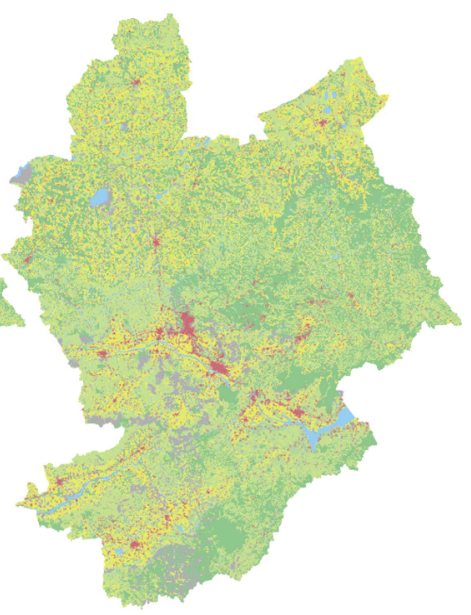

Figure 2 Land use pattern in Zhangjiakou city throughout 1989-2010

\subsection{Methods}

\subsubsection{Land use change measurement}

Based on the research, the land use dynamic degree (D) is used as a base indicator to describe the rate of land use change. The land use dynamic degree is calculated as follows (Zhang et al., 2014a):

$$
D_{i}=\sum_{i=1}^{N}\left|S_{b i}-S_{a i}\right| / 2 \sum_{i=1}^{N} S_{a i} \times T^{-1} \times 100 \%
$$

where $D_{i}$ is the dynamic degree of land type $i$ in the period $T$; $N$ is the number of land use type; $S_{a i}$ and $S_{b i}$ represent the area of land that uses type $i$ at the beginning and end of the period, respectively; and $T$ is the study period. The land use dynamic degree is an index that can quantitatively describe the regional difference in the rate of land use change and predict the trend in land use change (Wang and Bao, 1999). Moreover, the land use dynamic degree reflects the comprehensive influence of socio-economic activities on land use changes.

The land use change intensity index (C) can be used to recognize the main types of land use change, which can be expressed as follows (Luo et al., 2014): 


$$
C_{i}=A_{i} / \sum_{i=1}^{N} A_{i} \times 100 \%
$$

where $C_{i}$ represents the intensity index of land use change type $i$; $A_{i}$ is the area of land use change type $i$; and the value of $C_{i}$ is between 0 and 1 . The closer the value of $C_{i}$ to 1 , the more marked the land use change in a given region. Next, we can select the main types of land use changes by the rank of the value of $C_{i}$.

\subsubsection{Markov model}

The Markov model is used for state transition analysis and forecasting, and is suitable for predicting the conversion of land use in a given region (He et al., 2011; Hu et al., 2013). The Markov model is closely related to dynamic distributed-lag models and consists of two primary land components: the transition matrix and the transition probability matrix, which represent the number and the probability of land shifting from one land use type to other types in an observed period (Han et al., 2015). The land use distributions at the beginning $\left(S_{t}\right)$ and at the end $\left(S_{t+1}\right)$ of a time period, as well as a transition probability matrix $\left(P_{i j}\right)$ representing land use change that occurred during the defined period, are used to construct the Markov model, which is expressed as follows:

$$
S_{t+1}=S_{t} \times P_{i j}
$$

where $S_{t+1}$ and $S_{t}$ are the land use statuses at the time-points $t+1$ and $t$, respectively, and $P_{i j}$ is a transition probability matrix satisfying the following conditions:

$$
\begin{gathered}
0 \leqslant P_{i j} \leqslant 1 \\
\sum_{j=1}^{n} P_{i j}=1
\end{gathered}
$$

where $i$ and $j$ are the land use types at the time points $t+1$ and $t$, respectively.

\subsubsection{Landscape metrics analysis}

Landscape change is the visual sign of land use change (Feng et al., 2010). A large set of landscape metrics has been developed recently ( $\mathrm{Su}$ et al., 2012). The capacity of landscape metrics to indicate an ecological process has been discussed by several researchers ( $\mathrm{Su}$ et al., 2012; Jones et al., 2013; Fan and Myint, 2014; Tian et al., 2014). The selection of landscape metrics in this paper was based on the capacity to reflect the characteristics of landscape patterns for the study area. The landscape fragmentation index $(\mathrm{F})$, landscape shape index (LSI), perimeter-area fractal dimension index (PAFRAC), Shannon's diversity index (SHDI), interspersion and juxtaposition index (IJI), contagion index (CONTAG) and aggregation index (AI) were selected to describe the differences in landscape patterns in different scenarios. The landscape metrics above were calculated using Fragstats 4.2 software (Frazier, 2014).

3.2.4 The CLUE-S model and scenarios of land use changes

(1) The CLUE-S model

The land use simulation model CLUE-S (the Conversion of Land Use and its Effects at Small regional extent) utilizes the spatial dominant dynamic simulation model established by Wageningen University (Verburg and Veldkamp, 2004; Verburg and Overmars, 2009). The CLUE-S model includes a non-spatial demand module and spatially explicit land use 
allocation module, which needs to consider the following four elements: land use requirements, location characteristics and suitability, spatial policies and restrictions, and land use type specific conversion settings (Luo et al., 2010). The model can be developed to simulate land use change using empirically quantified relations between land use and its driving factors in combination with dynamic modeling of competition and interactions between the spatio-temporal dynamics of land use systems (Verburg et al., 2002; Verburg and Veldkamp, 2004). To date, the CLUE-S model has been widely used in international researches, and many scholars have conducted simulation by controlling different scenario settings and the total demand for the corresponding land patterns (Batisani and Yarnal, 2010; Verburg and Overmars, 2009; Luo et al., 2010; Wu et al., 2014; Zheng et al., 2015).

(2) Logistic regression

Generally, conversions of land use are expected to take place at locations that have the highest preference for a specific type of land use at a given moment. It can be calculated as a probability of a certain grid cell by logistic regression, as follows (Luo et al., 2010; Zeng et al., 2014; Wang et al., 2014; Zheng et al., 2015):

$$
\log \left(\frac{P_{i}}{1-P_{i}}\right)=\beta_{0}+\beta_{1} X_{1 i}+\beta_{2} X_{2 i}+\cdots+\beta_{n} X_{n i}
$$

where $P_{i}$ is the probability of a grid cell for the occurrence of the considered land use type $i$, the parameters $X$ refer to the driving factors, $n$ is the number of driving factors, and the coefficients $\beta$ are estimated through logistic regression using the actual land use pattern as a dependent variable. $\beta_{0}$ is the constant coefficient. $\operatorname{Exp}(\beta)$ values indicate the change in odds upon one unit change in the independent variable. When $\operatorname{Exp}(\beta)>1$, the probability increases upon an increase in the value of the independent variable. When $\operatorname{Exp}(\beta)<1$, the probability decreases. The relative operating characteristic (ROC) is used as a quantitative measure to evaluate the fit of the logistic regression model (Pontius and Schneider, 2001). The value of ROC ranges from 0.5 to 1.0. An ROC above 0.70 shows that the driving factors had a greater explanatory power for a certain land use type.

(3) Scenarios setting and land use elasticity

Based on local statistical socio-economic information from 1989 to 2010, and related land use planning and policies in Zhangjiakou city, we designed four variable settings of population increase, economic growth and urban development for the 10 years following 2010. Then, according to the combination of these settings, we defined four scenarios - namely, the land use planning scenario, natural development scenario, ecological-oriented scenario and farmland protection scenario - to predict land use demand for 2020 by applying various models, such as the Markov model, GM $(1,1)$ model and Grey prediction model. (1) The land use planning scenario: this scenario is the reference one, which may hasten the socio-economic development with an 11.7\% annual increase in GDP rate during 2010-2020. Total population may increase by $3.82 \%$ annually from 2010 to 2020 and the urbanization rate will increase to $54.2 \%$ in 2020 . Based on the planning targets of land use types from the Land Use Master Plan of Zhangjiakou (2006-2020), the structure of land use can be obtained by data interpolation according to the restrictions under land use planning in 2020. (2) The natural development scenario: this scenario almost keeps the present pace with socio-economic development, under which the GDP will increase by $12.0 \%$ annually and the total population will increase by $4.98 \%$ annually from 2010 to 2020 . In addition, the ten- 
dency of land use changes is predicted by applying time series methods and the GM $(1,1)$ model. (3) The ecological-oriented scenario: this scenario emphasizes protecting natural reserves, water resources, and biological diversity protection areas and requires all growth to be allocated outside these designated areas. In this scenario, the GDP will increase 10.0\% annually and the forest coverage rate will add up to $34.0 \%$ in 2020. (4) The farmland protection scenario: in this scenario, basic farmland will be designated as a restricted area in which the farmland cannot be converted into other land use types. The GDP will increase 9.6\% annually and the total population will increase by $4.53 \%$ annually from 2010 to 2020 under this scenario. The Grey prediction model and multi-objective programming model were used to simulate the land use demand for Zhangjiakou city in 2020.

The last decision rule concerns elasticity, which is an indicator of the conversion cost. For a given type of land use, the elasticity ranges from 0 (easy conversion) to 1 (irreversible change), and the value is positively related to the difficulty in converting this type of land use to other types (Wassenaar et al., 2007; Batisani and Yarnal, 2010). The transition matrix of land use types is calculated to ensure that the relative elasticity is extrapolated from current data. Based on the reference data in the study area during 1989-2010, the values of conversion elasticity for different land use types were tuned so that they were suitable for the calibration of the model. According to the defined scenarios, specific conversion elasticity values of land use types were defined and implemented in the model during 2010-2020 (Table 1).

Table 1 Values of land use type conversion elasticity (ELAS) in Zhangjiakou city

\begin{tabular}{lccccccc}
\hline \multicolumn{1}{c}{ Relative elasticity } & Farmland & $\begin{array}{c}\text { Garden } \\
\text { land }\end{array}$ & Forestland & Grassland & $\begin{array}{c}\text { Construc- } \\
\text { tion land }\end{array}$ & $\begin{array}{c}\text { Water } \\
\text { body }\end{array}$ & $\begin{array}{c}\text { Unused } \\
\text { land }\end{array}$ \\
\hline Land use planning scenario & 0.7 & 0.9 & 0.8 & 0.8 & 0.9 & 0.9 & 0.5 \\
Natural development scenario & 0.8 & 0.8 & 0.8 & 0.9 & 0.9 & 0.9 & 0.4 \\
Ecological-oriented scenario & 0.8 & 0.9 & 0.9 & 0.9 & 0.9 & 0.9 & 0.6 \\
Farmland protection scenario & 0.9 & 0.9 & 0.9 & 0.9 & 0.9 & 0.9 & 0.9 \\
\hline
\end{tabular}

\section{Results and analysis}

\subsection{Land use dynamics}

In this section, we have described the characteristics of land use dynamics by changes in land use quantity structure and land use types.

\subsubsection{Change in land use quantity structure}

Land use has changed significantly over the whole period from 1989 to 2010 in Zhangjiakou city (Table 2). The main types of land use in Zhangjiakou city are farmland, forestland and grassland, which accounted for about $85 \%$ of the total area, while garden land and other land use types occupied a relatively small proportion of the total area. Apparently, the area of farmland, grassland, water body and unused land shrank significantly throughout 1989-2010, decreasing by $11.09 \%, 2.82 \%, 18.20 \%$ and $31.27 \%$, respectively. By the end of 2010 , the area of garden land, forestland and construction land all increased, expanding by $5.71 \%$, 
$20.91 \%$ and $38.54 \%$, respectively, relative to 1989 . Over the two decades, farmland, forestland, construction land and unused land underwent marked changes. Specifically, farmland and unused land lost $1208.56 \mathrm{~km}^{2}$ and $679.17 \mathrm{~km}^{2}$, respectively, but forestland and construction land increased significantly by $1913.40 \mathrm{~km}^{2}$ and $385.49 \mathrm{~km}^{2}$, respectively.

Table 2 Land use changes in Zhangjiakou city throughout 1989-2010

\begin{tabular}{|c|c|c|c|c|c|c|}
\hline \multirow{2}{*}{ Land use types } & \multicolumn{2}{|c|}{1989} & \multicolumn{2}{|c|}{2010} & \multicolumn{2}{|c|}{ 1989-2010 } \\
\hline & $\begin{array}{l}\text { Area } \\
\left(\mathrm{km}^{2}\right)\end{array}$ & $\begin{array}{l}\text { Proportion } \\
(\%)\end{array}$ & $\begin{array}{l}\text { Area } \\
\left(\mathrm{km}^{2}\right)\end{array}$ & $\begin{array}{l}\text { Proportion } \\
(\%)\end{array}$ & $\begin{array}{c}\text { Change area } \\
\left(\mathrm{km}^{2}\right)\end{array}$ & $\begin{array}{c}\text { Change rate } \\
(\%)\end{array}$ \\
\hline Farmland & 10900.30 & 29.61 & 9691.74 & 26.33 & -1208.56 & -11.09 \\
\hline Garden land & 1412.81 & 3.84 & 1493.49 & 4.06 & 80.68 & 5.71 \\
\hline Forest land & 9149.40 & 24.86 & 11062.80 & 30.06 & 1913.4 & 20.91 \\
\hline Grassland & 11207.94 & 30.45 & 10891.42 & 29.59 & -316.52 & -2.82 \\
\hline Construction land & 1000.24 & 2.72 & 1385.73 & 3.77 & 385.49 & 38.54 \\
\hline Water body & 963.16 & 2.62 & 787.84 & 2.14 & -175.32 & -18.20 \\
\hline Unused land & 2171.62 & 5.90 & 1492.45 & 4.05 & -679.17 & -31.27 \\
\hline
\end{tabular}

The rate of land use change in different periods is illustrated by the land use dynamic degree (Table 3). From 1989 to 2000, the value of the land use integrated dynamic degree was $2.21 \%$, which indicated that the rate of land use change was relatively slow. Meanwhile, from 2000 to 2010, the value of the land use integrated dynamic degree was $3.96 \%$, which demonstrated that the rate of land use change had accelerated compared with that of the previous period and that the effects of socio-economic activities on the land use pattern had intensified. At the same time, the area of farmland, grassland, water body and unused land decreased gradually: the rate changed from $0.27 \%, 0.15 \%, 0.88 \%$ and $0.73 \%$ to $0.83 \%$, $0.11 \%, 0.94 \%$ and $2.53 \%$, respectively, while the area of garden land, forestland and construction land increased continuously. Furthermore, the rate of garden land decreased from $0.51 \%$ during the former period to $0.01 \%$ during the latter period, and that of forestland and construction land increased from $0.56 \%$ and $1.32 \%$ to $1.39 \%$ and $2.10 \%$, respectively.

Table 3 Rate of land use change during different periods in Zhangjiakou city

\begin{tabular}{ccccccccc}
\hline \multirow{2}{*}{ Periods } & \multicolumn{9}{c}{ Land use dynamic degree (\%) } & \multicolumn{2}{c}{\begin{tabular}{c} 
Integrated \\
dynamic \\
\cline { 2 - 9 }
\end{tabular}} & $\begin{array}{c}\text { Farm- } \\
\text { land }\end{array}$ & $\begin{array}{c}\text { Garden } \\
\text { land }\end{array}$ & Forest land Grassland & $\begin{array}{c}\text { Construction } \\
\text { land }\end{array}$ & Water body & $\begin{array}{c}\text { Unused } \\
\text { land }\end{array}$ & $\begin{array}{c}\text { degree }(\%) \\
\text { 1989-2000 }\end{array}-0.27$ & 0.51 & 0.56 & -0.15 & 1.32 & -0.88 & -0.73 & 2.21 \\
$2000-2010$ & -0.83 & 0.01 & 1.39 & -0.11 & 2.10 & -0.94 & -2.53 & 3.96 \\
\hline
\end{tabular}

On the spatial scale, the expansion of construction land was strikingly clear from the urban center to the outskirts (Figure 2). The direction of construction land expansion was primarily along the highways and national roads, from administrative districts (i.e, Qiaoxi, Qiaodong, Xiahuayuan and Xuanhua districts) to Zhangbei, Yangyuan and Yuxian counties in the suburbs. Meanwhile, the area with growth in forestland mainly occurred in Bashang Plateau and its neighboring mountainous areas. In addition, the reduction in farmland was 
mainly located in administrative districts and their surrounding regions in Zhangjiakou city. This indicated that the urban-rural fringe was the area most sensitive to urbanization. With the socio-economic development, the conflict between urban development and farmland preservation was found to be gradually increasing. The administrative districts and their surrounding regions were the hot spots witnessing much faster land use changes.

\subsubsection{Change in land use types}

By overlaying the 1989 and 2010 land use maps, the area changes in land use types in the study area over the two decades were further calculated (Table 4). Investigating from the conversion direction of land use types revealed that there was an obvious interaction among farmland, forestland, grassland, construction land and unused land. Changes mainly occurred in Bashang Plateau, river valley and mountainous areas. The total changed area throughout 1989-2010 was $4759.14 \mathrm{~km}^{2}$, accounting for $12.93 \%$ of the study area. As shown in Table 4, land use transformation types were characterized by grassland to forestland, and by farmland to forestland and grassland. Among the transformation types of land use, the area of grassland to forestland, farmland to forestland, grassland to farmland, unused land to forestland, unused land to grassland, farmland to construction land, and farmland to garden land represented more than $80 \%$ of the area undergoing land use change. It was obvious that land use changes in 1989-2010 were dramatic and dominated by these seven transformation types. During 1989-2000, the conversions of grassland to forestland, and farmland to grassland, comprised the principal transformations in land use. Construction land expansion was mainly derived from farmland, and unused land was changed into forestland and grassland. However, throughout 2000-2010, the conversions of farmland and grassland to forestland accounted for $45.52 \%$ of the total area of land use changes, which was mainly affected by the Grain for Green Project. The conversion of farmland to forestland mainly occurred in Bashang Plateau and its neighboring mountainous areas around the junction between Chongli county and Chicheng county. The conversion of grassland to forestland mainly occurred in mountainous areas involving Chongli, Chicheng and Zhuolu counties. The conversion of farmland to construction land was distributed in administrative districts and their surrounding regions, and was caused by the urbanization process and the development of infrastructure.

Table 4 Main types of land use change in Zhangjiakou city throughout 1989-2010

\begin{tabular}{lc||lr||lrl}
\hline \multicolumn{1}{c|}{$1989-2000$} & & & \multicolumn{2}{c||}{ 2000-2010 } & & \multicolumn{2}{c}{$1989-2010$} \\
\hline Transformation type & $\mathrm{C}_{\mathrm{i}}(\%)$ & Transformation type & $\mathrm{C}_{\mathrm{i}}(\%)$ & Transformation type & $\mathrm{C}_{\mathrm{i}}(\%)$ \\
\hline Grassland to Forestland & 29.61 & Grassland to Forestland & 27.69 & Grassland to Forestland & 29.15 \\
Farmland to Grassland & 18.67 & Farmland to Forestland & 17.83 & Farmland to Forestland & 16.26 \\
Farmland to Forestland & 8.05 & Grassland to Farmland & 10.96 & Grassland to Farmland & 11.30 \\
Unused land to Forestland & 6.65 & Unused land to Grassland & 10.09 & Unused land to Forestland & 8.44 \\
Farmland to Construction land & 6.21 & Unused land to Forestland & 8.55 & Unused land to Grassland & 8.21 \\
Grassland to Farmland & 5.17 & Farmland to Construction land & 5.67 & Farmland to Construction land & 6.04 \\
Unused land to Grassland & 4.16 & Farmland to Garden land & 3.65 & Farmland to Garden land & 4.21 \\
Other 31 types & 21.48 & Other 43 types & 15.56 & Other 36 types & 16.39 \\
Total & 100.00 & Total & 100.00 & Total & 100.00 \\
\hline
\end{tabular}




\subsection{Regression analysis of land use change}

The CLUE-S model requires setting the relationship between location factors and different land use (Zheng et al., 2015). In this study, a logistic regression model was used to explore the relationship between land use change and the related driving factors (Braimoh and Onishi, 2007). Certain driving factors - including landform $\left(X_{1}\right)$, soil organic matter $\left(X_{2}\right)$, elevation $\left(\mathrm{X}_{3}\right)$, slope $\left(\mathrm{X}_{4}\right)$, aspect $\left(\mathrm{X}_{5}\right)$, distance to the nearest river $\left(\mathrm{X}_{6}\right)$, distance to the nearest town center $\left(\mathrm{X}_{7}\right)$, distance to the nearest county center $\left(\mathrm{X}_{8}\right)$, distance to the nearest main road $\left(\mathrm{X}_{9}\right)$, distance to the nearest railway $\left(\mathrm{X}_{10}\right)$, population density $\left(\mathrm{X}_{11}\right)$, urbanization rate $\left(\mathrm{X}_{12}\right)$, economic density $\left(\mathrm{X}_{13}\right)$, fixed assets investment $\left(\mathrm{X}_{14}\right)$ and per-capita net income of farmers $\left(\mathrm{X}_{15}\right)$ - were selected for the purpose of analyzing the location suitability of a certain grid to be devoted to a land use type.

As shown in Table 5, the ROC test statistics for various land use types were all above 0.70 . This revealed that the factors selected performed well in terms of explaining the land use pattern of the study area, but different driving factors resulted in some differences in various land use types. Slope was a negative explanatory variable for farmland, suggesting that steep areas with higher elevation and slope would experience a smaller probability of

Table 5 Logistic regression results of the spatial distribution of land use types in Zhangjiakou city throughout 2000-2010

\begin{tabular}{|c|c|c|c|c|c|c|c|c|c|c|c|c|c|c|}
\hline \multirow{2}{*}{ Drivers } & \multicolumn{2}{|c|}{ Farmland } & \multicolumn{2}{|c|}{ Garden land } & \multicolumn{2}{|c|}{ Forestland } & \multicolumn{2}{|c|}{ Grassland } & \multicolumn{2}{|c|}{$\begin{array}{c}\text { Construction } \\
\text { land }\end{array}$} & \multicolumn{2}{|c|}{ Water body } & \multicolumn{2}{|c|}{ Unused land } \\
\hline & $\beta$ & $\operatorname{EXP}(\beta)$ & $\beta$ & $\operatorname{EXP}(\beta)$ & $\beta$ & $\operatorname{EXP}(\beta)$ & $\beta$ & $\operatorname{EXP}(\beta)$ & $\beta$ & $\operatorname{EXP}(\beta)$ & $\beta$ & $\operatorname{EXP}(\beta)$ & $\beta$ & $\operatorname{EXP}(\beta)$ \\
\hline $\mathrm{X}_{1}$ & -0.0228 & 0.9775 & 0.0117 & 1.0118 & 0.0250 & 1.0253 & 0.0117 & 1.0118 & -0.0453 & 0.9557 & -0.0730 & 0.9296 & - & - \\
\hline $\mathrm{X}_{2}$ & - & - & - & - & -0.0340 & 0.9666 & 0.0441 & 1.0451 & - & - & - & - & - & - \\
\hline $\mathrm{X}_{3}$ & -0.0009 & 0.9991 & -0.0093 & 0.9908 & 0.0008 & 0.9992 & 0.0227 & 1.0229 & -0.0026 & 0.9974 & -0.0020 & 0.9980 & 0.0185 & 1.0187 \\
\hline $\mathrm{X}_{4}$ & -0.2729 & 0.7612 & -0.4639 & 0.6288 & 0.0345 & 1.0351 & -0.1669 & 0.8463 & -0.197 & 0.8212 & 0.0276 & 1.0280 & 0.0415 & 1.0424 \\
\hline $\mathrm{X}_{5}$ & 0.0006 & 1.0006 & - & - & - & - & -0.0005 & 0.9995 & - & - & - & - & - & - \\
\hline $\mathrm{X}_{6}$ & -0.0065 & 0.9935 & 0.0568 & 1.0585 & -0.0120 & 0.9881 & 0.0154 & 1.0155 & -0.0163 & 0.9839 & -0.0545 & 0.9470 & - & - \\
\hline $\mathrm{X}_{7}$ & -0.0083 & 0.9917 & 0.0435 & 1.0445 & 0.0100 & 1.0100 & -0.0066 & 0.9935 & -0.0189 & 0.9813 & - & - & -0.0024 & 0.9976 \\
\hline $\mathrm{X}_{8}$ & -0.0285 & 0.9719 & - & - & 0.0269 & 1.0272 & - & - & -0.1232 & 0.8841 & 0.0999 & 1.1051 & -0.1026 & 0.9025 \\
\hline $\mathrm{X}_{9}$ & - & - & -0.0472 & 0.9539 & 0.0055 & 1.0055 & 0.0019 & 1.0019 & - & - & 0.0106 & 1.0106 & -0.0159 & 0.9843 \\
\hline $\mathrm{X}_{10}$ & - & - & - & - & - & - & 0.009 & 1.0091 & - & 0.9998 & - & - & -0.0852 & 0.9183 \\
\hline $\mathrm{X}_{11}$ & -0.0009 & 0.9991 & 0.0015 & 1.0015 & -0.0008 & 0.9992 & -0.0007 & 0.9993 & -0.0002 & - & - & - & - & - \\
\hline $\mathrm{X}_{12}$ & -0.0282 & 0.9722 & 0.0354 & 1.0360 & -0.0297 & 0.9707 & -0.0046 & 0.9954 & - & - & - & - & -0.1562 & 0.8554 \\
\hline $\mathrm{X}_{13}$ & 0.0007 & 1.0007 & -0.0018 & 0.9982 & -0.0002 & 0.9998 & -0.0004 & 0.9996 & 0.0004 & 1.0004 & - & - & 0.0014 & 1.0014 \\
\hline $\mathrm{X}_{14}$ & 0.0044 & 1.0045 & 0.0074 & 1.0074 & -0.0034 & 0.9966 & -0.0038 & 0.9962 & 0.0014 & 1.0014 & - & - & 0.0243 & 1.0246 \\
\hline $\mathrm{X}_{15}$ & -0.0001 & 0.9999 & 0.0004 & 1.0004 & - & - & - & - & - & - & 0.0002 & 1.0002 & -0.0002 & 0.9998 \\
\hline Constant & -0.1458 & 0.8643 & -12.7820 & 0.0001 & -8.7846 & 0.0002 & -9.8221 & 0.0001 & -4.4890 & 0.0112 & -2.0367 & 0.1305 & -9.9562 & 0.0014 \\
\hline ROC value & 0.8 & & 0.8 & & 0.8 & & & & & 915 & & & & 798 \\
\hline
\end{tabular}

Note: The mark "-_" denotes the factors removed. $\mathrm{X}_{1}$-landform, $\mathrm{X}_{2}$-soil organic matter, $\mathrm{X}_{3}$-elevation, $\mathrm{X}_{4}-$ slope, $\mathrm{X}_{5}$-aspect, $\mathrm{X}_{6}$-distance to the nearest river, $\mathrm{X}_{7}$-distance to the nearest town center, $\mathrm{X}_{8}$-distance to the nearest county center, $\mathrm{X}_{9}$-distance to the nearest main road, $\mathrm{X}_{10}$-distance to the nearest railway, $\mathrm{X}_{11}$-population density, $\mathrm{X}_{12}$-urbanization rate, $\mathrm{X}_{13}$-economic density, $\mathrm{X}_{14}$-fixed assets investment, $\mathrm{X}_{15}$-per-capita net income of farmers. 
farmland. The probability distribution of farmland decreased 0.2729 times when slope increased by one unit. Distance to the nearest river and distance to the nearest town center were positive explanatory variables of garden land, which was located in river valley, as well as the area around Guanting Reservoir. Slope became an important factor restricting the development of garden land in Zhangjiakou city. Soil was also an important factor shaping land use patterns. However, soil organic matter and slope played an important role in the distribution of forestland and grassland. Forestland was mainly distributed in areas with high elevation and slope as well as in certain remote regions, while grassland was distributed in Bashang Plateau, i.e., Kangbao, Shangyi, Zhangbei and Guyuan counties. Thus, many factors affected the distribution of construction land. Moreover, elevation, slope, distance to the nearest river, distance to the nearest town center, and distance to the nearest county center were negative explanatory variables of construction land. However, economic density and fixed assets investment were positive determinants of construction land. In addition, physical variables had different effects on the distribution of water body.

\subsection{Simulation of land use demand}

Based on the land use change from 1989 to 2010, the Markov model, GM (1, 1) model, Grey prediction model and multi-objective programming model were used to predict the demand for different land use types in 2020 according to the four future scenarios defined above. The prediction results were presented in Table 6. As shown in the table, there was significant difference in the demand for various land use types under different scenarios.

Table 6 The prediction results of land use under different scenarios $\left(\mathrm{km}^{2}\right)$

\begin{tabular}{llccccccc}
\hline Year & \multicolumn{1}{c}{ Scenario design } & Farmland & $\begin{array}{c}\text { Garden } \\
\text { land }\end{array}$ & Forestland & Grassland & $\begin{array}{c}\text { Construction } \\
\text { land }\end{array}$ & $\begin{array}{c}\text { Water } \\
\text { body }\end{array}$ & $\begin{array}{c}\text { Unused } \\
\text { land }\end{array}$ \\
\hline 2010 & Actual land use & 9691.74 & 1493.49 & 11062.80 & 10891.42 & 1385.73 & 787.84 & 1492.45 \\
\hline & $\begin{array}{l}\text { Land use planning scenario } \\
\text { Natural development }\end{array}$ & 8721.00 & 1500.49 & 12932.90 & 10634.90 & 1535.00 & 725.48 & 755.70 \\
$\begin{array}{l}\text { scenario } \\
\begin{array}{l}\text { Ecological-oriented } \\
\text { scenario }\end{array}\end{array}$ & 8288.79 & 1521.89 & 13061.68 & 10819.07 & 1744.20 & 722.96 & 646.88 \\
$\begin{array}{l}\text { Farmland protection } \\
\text { scenario }\end{array}$ & 9429.17 & 1562.82 & 11543.47 & 10712.17 & 1516.48 & 712.91 & 1328.45 \\
\hline
\end{tabular}

\subsection{Simulation of land use scenarios}

Based on the results of the logistic regression model and the transition matrix, the CLUE-S model was used to simulate the distribution of land use pattern in 2010. The accuracy of the temporal predictions of the CLUE-S model was analyzed based on the Kappa index by comparing the actual land use map in 2010 with the simulated map of land use pattern for Zhangjiakou city in 2010 (Figure 3). The Kappa statistic was employed to evaluate the accuracy of the model (Pontius, 2000). The value of the Kappa statistic was 0.902 throughout the temporal scale of 10 years during 2000-2010, which indicated that the consistency was good between the simulated map and the actual land use map. Moreover, this showed that the model was reliable for Zhangjiakou city and could be used to predict future land use patterns under different scenarios (Pan et al., 2011). 
Combined with the land use demand under different scenarios, land transfer rules, related driving factors and the calibrated model settings, the CLUE-S model was used to simulate the distribution of land use patterns of Zhangjiakou city in 2020 (Figure 4). As shown in

(a) 2010 Actual land use

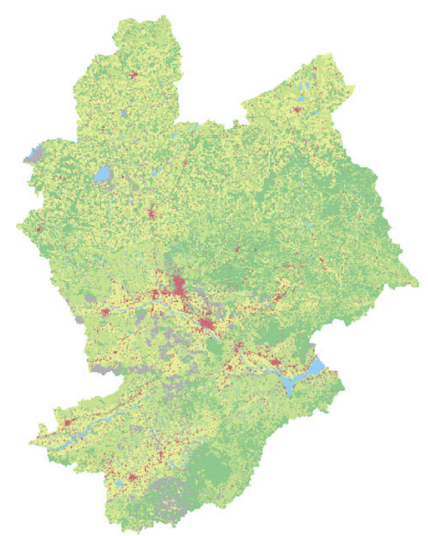

(b) 2010 Land use simulation

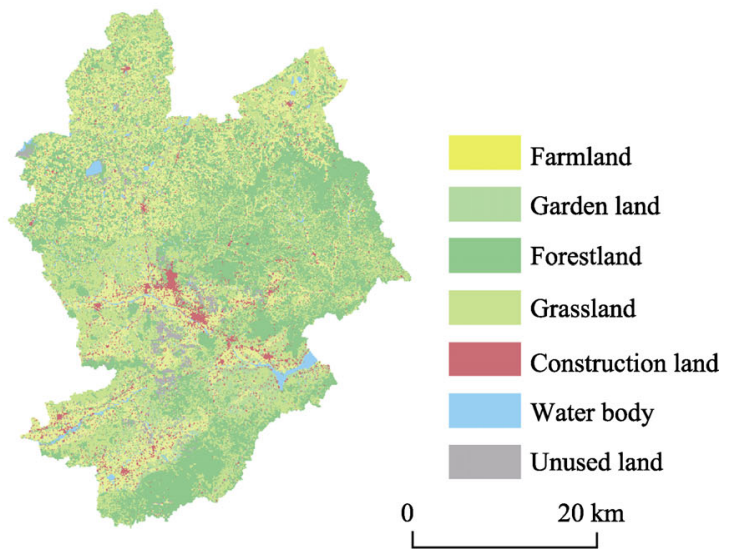

Figure 3 Land use map (a) and simulation map (b) of Zhangjiakou city in 2010

(a) Land use planning scenario

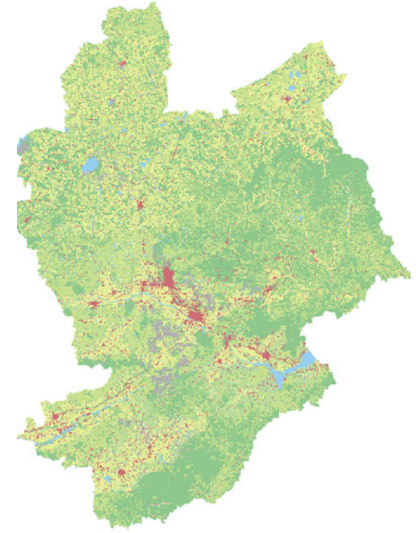

(c) Ecological-oriented scenario

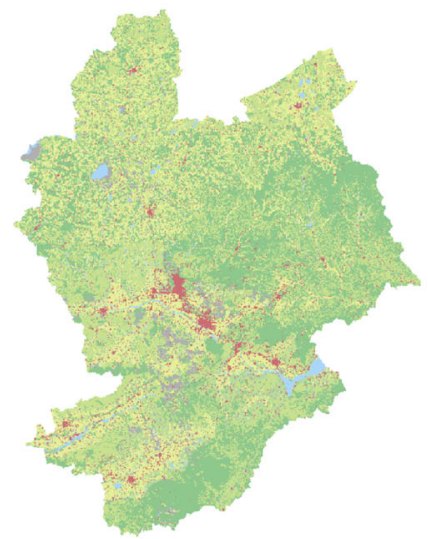

(b) Natural development scenario

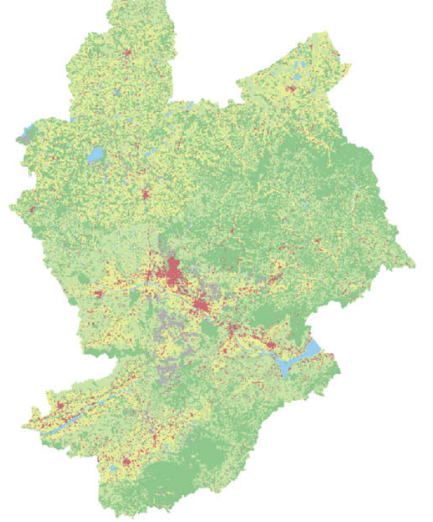

(d) Farmland protection scenario

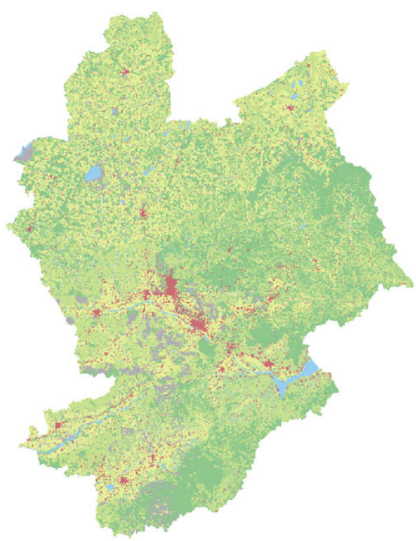

Farmland

Garden land

Forestland

Grassland

Construction land

Water body

Unused land

0

$20 \mathrm{~km}$

Figure 4 Land use simulation maps of Zhangjiakou city in 2020

(a) Land use planning scenario; (b) Natural development scenario; (c) Ecological-oriented scenario; (d) Farmland protection scenario 
Figure 4, farmland, forestland and grassland were the main land use types. Farmland was primarily concentrated in mid river valley. Forestland and grassland were mainly distributed in Bashang Plateau and its neighboring mountainous areas, as well as southern mountainous areas. In addition, land use types underwent different dynamics under the four scenarios, as follows:

(1) Land use planning scenario (reference scenario, Figure 4a). Apparently, farmland, grassland, water body and unused land shrank significantly in 2020 compared with 2010, while garden land, forestland and construction land increased. During 2010-2020, forestland increased by $1900.61 \mathrm{~km}^{2}$. The increase in forestland was mainly derived from farmland and unused land. Thus, the conversion of farmland to forestland was expected to be distributed in the Bashang Plateau and the southern mountainous areas, accounting for $49.63 \%$ of the total area in new forestland. In addition, the conversion area of unused land to forestland was $664.20 \mathrm{~km}^{2}$, and was mainly located in the mountainous areas of Wanquan and Yuxian counties. Moreover, the expansion of construction land was concentrated in administrative districts and their surrounding regions.

(2) Natural development scenario (Figure 4b). There was an obvious expansion of construction land with a concentrated distribution in 2020. Compared with the land use pattern in 2010 , construction land increased by $358.47 \mathrm{~km}^{2}$, which had expanded by occupying farmland and unused land. The conversion of farmland to construction land was $195.48 \mathrm{~km}^{2}$, which mainly occurred in districts and their surrounding regions. The conversion of unused land to construction land was $128.79 \mathrm{~km}^{2}$, and had been concentrated in the regions along roads and river valley of Yangyuan county. Forestland increased by $1998.88 \mathrm{~km}^{2}$. The area of the new forestland from farmland was $1142.62 \mathrm{~km}^{2}$, which mostly occurred in the Bashang Plateau and mountainous areas around the junction among Zhangbei, Guyuan, Chongli and Chicheng counties as well as the junction between Zhuolu and Yuxian counties with high elevation. The area of new forestland from unused land in the mountainous areas of Huai'an and Yuxian counties, occurring mostly from 2010 to 2020 , was $710.19 \mathrm{~km}^{2}$.

The results of the simulation in the natural development scenario were similar to those in the land use planning scenario, but the changes in land use types were more fundamental. There were significant differences in most land use types, including farmland, forestland, grassland, construction land and unused land. In the natural development scenario, the area of farmland and unused land was $432.21 \mathrm{~km}^{2}$ and $108.82 \mathrm{~km}^{2}$ less, respectively, than that in the land use planning scenario, while the area of forestland, grassland and construction land was $128.78 \mathrm{~km}^{2}, 184.17 \mathrm{~km}^{2}$ and $209.20 \mathrm{~km}^{2}$, respectively, more than that in the refence scenario. On the spatial scale, some differences were found to be distributed in the Bashang Plateau and mountainous areas between the two scenarios. More farmland converted to forestland than the reference scenario in the Bashang Plateau and its neighboring mountainous areas, and much more farmland was used for construction in Qiaodong district. In addition, more conversion of unused land to construction land primarily occurred in Zhangbei, Yangyuan and Yuxian counties under the natural development scenario.

(3) Ecological-oriented scenario (Figure 4c). In this scenario, farmland and unused land shrank by $847.62 \mathrm{~km}^{2}$ and $512.72 \mathrm{~km}^{2}$, respectively, while construction land experienced slow expansion and forestland underwent an obvious expansion. During 2010-2020, forestland increased by $1415.34 \mathrm{~km}^{2}$, which was mainly derived from farmland, grassland and unused land, with $709.20 \mathrm{~km}^{2}, 120.51 \mathrm{~km}^{2}, 455.22 \mathrm{~km}^{2}$, respectively. The conversion of 
farmland to forestland was mostly located in the hilly areas, river valleys and mountainous areas. The predicted grassland/unused land-forestland conversion areas mainly occurred in the following regions: the hilly area in Bashang Plateau, the northeast mountainous areas of Yanshan Mountain, and the southern mountainous area of Xiaowutai.

Less change in land use occurred under the ecological-oriented scenario from 2010 to 2020. This showed that there was less demand for garden land, forestland and construction land in this scenario. The area of forestland was $454.76 \mathrm{~km}^{2}$ less than that in the land use planning scenario, which was mainly located in Shangyi, Zhangbei, Huai'an and Yuxian counties. Meanwhile, more demand for farmland, grassland and unused land was required in the ecological-oriented scenario. The area of farmland, grassland and unused land was $123.12 \mathrm{~km}^{2}, 122.07 \mathrm{~km}^{2}$ and $224.03 \mathrm{~km}^{2}$, respectively, more than that in the reference scenario. There was more grassland, which was mainly distributed in mountainous areas within Chicheng, Yuxian and Zhuolu counties. Moreover, more unused land was scattered in high-altitude areas in Shangyi, Zhangbei, Huai'an and Yuxian counties.

(4) Farmland protection scenario (Figure 4d). This study assumed that the land use was under a strict farmland protection policy from 2010 to 2020. Comparing the simulated results in 2020 with the actual map, the changes in farmland and forestland were relatively obvious. In particular, farmland was primarily converted to forestland, with an area of $225.63 \mathrm{~km}^{2}$. Moreover, grassland/unused land-farmland conversion mostly occurred in regions of the surrounding districts (i.e., Huai'an county, Xuanhua county) and the mountainous area within Yuxian county. Similar to the above scenarios, farmland was concentrated in the flat areas. Construction land was scattered in Zhangjiakou city, which was mainly surrounded by farmland.

Compared with the land use planning scenario in 2020, this showed that there was less demand for forestland and more demand for farmland and unused land under the farmland protection scenario. Much more unused land existed in the mountainous areas of Huai'an and Yuxian counties. However, more farmland was scattered in the region around the junction among Guyuan, Zhangbei, Chongli and Chicheng counties. However, the conversion of farmland to construction land and forestland still existed in the mountainous areas of Huai'an, Chicheng, Chongli and Yuxian counties, which indicated that Zhangjiakou would continue to face pressure in farmland protection.

\subsection{Landscape metrics analysis}

The heterogeneity of landscape can be used to characterize the stability and safety of an ecological system (Feng et al., 2010; Jones et al., 2013; Wang et al., 2014), which can be used to reflect the simulation results of land use patterns under different scenarios. Compared with the landscape pattern of land use in 2010, the study area will exhibit more homogeneity and its landscape pattern will become less marked in 2020, evidenced by the reduction in the fragmentation index (F) and landscape shape index (LSI), and the increase in the contagion (CONTAG) and aggregation index (AI) (Table 7). Grassland and unused land will become more fragmented, while other land use types will become less fragmented in 2020. A reduction in PAFRAC for farmland and water body indicates that patch shapes will tend to be simpler. However, an increase in PAFRAC and LSI of construction land will occur from 2010 to 2020 (Table 8). 
Table 7 Landscape metrics of Zhangjiakou city under different scenarios

\begin{tabular}{|c|c|c|c|c|c|c|c|}
\hline Land use scenario & $\mathrm{F}$ & LSI & PAFRAC & SHDI & IJI & CONTAG & $\mathrm{AI}$ \\
\hline 2010 Actual land use & 0.0097 & 131.4746 & 1.5738 & 1.5691 & 73.8408 & 29.6276 & 59.4424 \\
\hline $\begin{array}{l}\text { Land use planning scenario } \\
\text { (Reference scenario) }\end{array}$ & 0.0090 & 126.4539 & 1.5730 & 1.5875 & 73.9858 & 32.2885 & 61.0127 \\
\hline Natural development scenario & 0.0089 & 126.6271 & 1.5768 & 1.5519 & 73.2345 & 32.5534 & 60.9583 \\
\hline Ecological-oriented scenario & 0.0093 & 128.0227 & 1.5744 & 1.5706 & 72.5546 & 31.1907 & 60.5223 \\
\hline Farmland protection scenario & 0.0095 & 129.8600 & 1.5750 & 1.5733 & 70.5517 & 30.0865 & 59.9485 \\
\hline
\end{tabular}

Table 8 Class metrics of Zhangjiakou city under different scenarios

\begin{tabular}{|c|c|c|c|c|c|c|c|c|}
\hline & & Farmland & $\begin{array}{c}\text { Garden } \\
\text { land }\end{array}$ & Forestland & Grassland & $\begin{array}{c}\text { Construction } \\
\text { land }\end{array}$ & $\begin{array}{l}\text { Water } \\
\text { body }\end{array}$ & $\begin{array}{c}\text { Unused } \\
\text { land }\end{array}$ \\
\hline \multirow{3}{*}{2010 Actual land use } & $\mathrm{F}$ & 0.0055 & 0.0177 & 0.0068 & 0.0076 & 0.0447 & 0.0377 & 0.0181 \\
\hline & PAFRAC & 1.6025 & 1.5709 & 1.5594 & 1.6022 & 1.4809 & 1.5045 & 1.4974 \\
\hline & LSI & 127.6094 & 67.2558 & 126.8260 & 141.3391 & 82.5360 & 51.7500 & 57.0814 \\
\hline \multirow{3}{*}{$\begin{array}{l}\text { Land use planning } \\
\text { Scenario } \\
\text { (Reference scenario) }\end{array}$} & $\mathrm{F}$ & 0.0048 & 0.0176 & 0.0057 & 0.0079 & 0.0427 & 0.0345 & 0.0204 \\
\hline & PAFRAC & 1.5989 & 1.5712 & 1.5613 & 1.6038 & 1.4983 & 1.5014 & 1.5112 \\
\hline & LSI & 118.6083 & 66.3977 & 123.0988 & 141.0610 & 85.2759 & 47.5944 & 44.5054 \\
\hline \multirow{3}{*}{$\begin{array}{l}\text { Natural development } \\
\text { scenario }\end{array}$} & $\mathrm{F}$ & 0.0048 & 0.0170 & 0.0054 & 0.0076 & 0.0417 & 0.0340 & 0.0182 \\
\hline & PAFRAC & 1.6003 & 1.5693 & 1.5667 & 1.6028 & 1.5134 & 1.4991 & 1.5189 \\
\hline & LSI & 116.2158 & 63.9960 & 125.3124 & 141.2334 & 90.3011 & 46.9441 & 40.1000 \\
\hline \multirow{3}{*}{$\begin{array}{l}\text { Ecological-oriented } \\
\text { scenario }\end{array}$} & $\mathrm{F}$ & 0.0049 & 0.0177 & 0.0059 & 0.0077 & 0.0434 & 0.0339 & 0.0214 \\
\hline & PAFRAC & 1.5992 & 1.5727 & 1.5622 & 1.6033 & 1.5106 & 1.4971 & 1.5078 \\
\hline & LSI & 119.4530 & 66.4690 & 123.6671 & 141.1055 & 89.5018 & 46.3911 & 50.6555 \\
\hline \multirow{3}{*}{$\begin{array}{l}\text { Farmland protection } \\
\text { scenario }\end{array}$} & $\mathrm{F}$ & 0.0052 & 0.0170 & 0.0066 & 0.0077 & 0.0435 & 0.0342 & 0.0195 \\
\hline & PAFRAC & 1.6008 & 1.5731 & 1.5595 & 1.6031 & 1.4988 & 1.4941 & 1.5091 \\
\hline & LSI & 124.5201 & 67.0455 & 124.7448 & 140.7728 & 85.5211 & 46.1638 & 56.3827 \\
\hline
\end{tabular}

4.5.1 Landscape-level metric analysis

The results of landscape-level metrics analysis are shown in Table 7. There are many superior indices in land use planning scenarios, including the landscape shape index (LSI), fractal dimension index (PATRAC), Shannon's diversity index (SHDI), interspersion and juxtaposition index (IJI) and aggregation index (AI). There are significant characteristics of landscape pattern at the landscape level in this scenario. LSI and PATRAC are at their lowest value in this scenario, indicating that the landscape is more regular. The natural development scenario reflects the relevant difference in the landscape pattern of land use. The fragmentation index (F) and contagion index (CONTAG) are the superior indices in this scenario, whose landscape is less fragmented with better spatial connectivity. It is indicated that appropriate human interventions can regulate the spatial form of land use effectively to avoid excessive dispersion of the landscape. The increases in SHDI, IJI and AI suggest that landscape diversity becomes more significant and the distribution of landscape patches tends to be accumulative. However, there is no superior index under an ecological-oriented scenario 
or farmland protection scenario, in which the landscape pattern exhibits more fragmented and homogeneous. Given all that, the combination of land use types in land use planning scenarios is less marked than other scenarios. In this section, reductions in F and LSI and increases in CONTAG and AI indicate that landscapes become less fragmented under different scenarios. At the same time, the spatial structures of landscapes tend to be simpler, while shapes of landscape will become more regular in 2020 than in 2010. Moreover, the aggregation and connectivity of land use patterns will increase gradually. The complex changes in landscape patterns are examined with three metrics (i.e., PAFRAC, SHDI and IJI). In addition to SHDI, its increase indicates that the heterogeneity and diversity of landscapes increases under different scenarios, except with the natural development scenario.

\subsubsection{Class-level metric analysis}

Table 8 shows the results from the landscape pattern changes at class level under different scenarios. The land-use classes incorporated into the class-level metric analysis were farmland, garden land, forestland, construction land, water body and unused land. Fragmentation index (F), fractal dimension index (PATRAC) and landscape shape index (LSI) reveal important information about the landscape characteristics of each land use type under different scenarios. In the land use planning scenario, F and PAFRAC are at the highest values for landscapes of grassland and water body, indicating that their landscape patches become fragmented and more complex during 2010-2020. Furthermore, landscapes of forestland and construction land are characterized by the lowest values of LSI. This finding shows that the effective protection of landscapes of grassland and water body cannot be achieved by the total amount of control in the transition zone between the cropping area and the nomadic area. Considering the quantity demand of farmland and construction land, some guidance on the spatial changes in the major land use types by human factors must be enhanced to realize reasonable allocation of land resources and promote the coordinated development of socio-ecological systems (S-ESs). Under the natural development scenario, the landscape is characterized by low fragmentation of land use types and more complex shapes of construction land and unused land with high PAFRAC value. In addition to forestland and grassland, LSI is at its highest value, indicating the concentrated condition. Owing to the economic development and Grain for Green Project in the study area, farmland is occupied by construction land and ecological land. The changes in land use types dominated by human activities have an important influence on the landscape pattern of land use in Zhangjiakou city. Under the ecological-oriented scenario, there is low fragmentation of landscapes of garden land and unused land. The landscape of ecological land gets effective protection, which contributes to the policy of the Grain for Green Project as well as the Sandstorm-Control Program. Under the farmland protection scenario, the landscapes of farmland, garden land, forestland and construction land exhibit more fragmented and heterogeneous. Moreover, patch shapes of farmland and garden land will become more complex and irregular than other scenarios in 2020. However, a reduction in the fractal dimension index (PATRAC) of grassland and water body suggests that their structures present simpler and more regular. According to the above analysis, the strict measures of farmland protection cannot effectively relieve the potential impact of the landscape pattern, which was caused by human activities in the environmental fragile zone. 


\section{Discussion}

Land use changes are caused by both natural factors and human activities (Vitousek et al., 1997; Liao et al., 2011). Since 1989, human activities, such as population growth, rapid economic development, increased urbanization and land use policy, have had a major impact on land use changes in Zhangjiakou city. In addition, administrative policies and natural factors have played important roles in land use changes. From 1989 to 2010, the land use structure of Zhangjiakou city changed dramatically, as shown in Table 2. Land use changes were characterized by the decline in farmland, grassland, water body and unused land, and the increase in garden land, forestland and construction land. Throughout 1989 to 2000, ecological deterioration and farmers' poverty were the two critical problems of Zhangjiakou city. Owing to low productivity, population pressure and unreasonable human activities, the irrational land use mode of over-reclamation, overgrazing and deforestation prevailed in this area. The conversions of grassland to forestland and farmland to grassland constituted the main direction of land use changes. The economic development was at a lower level owing to unreasonable industrial structure and serious land desertification during the same period. As a result, the land use intensity and rate of land use change were much lower in Zhangjiakou city. All these indicated the characteristics of land use changes in farming-pastoral zones. At the same time, throughout 2000-2010, Zhangjiakou city experienced rapid socio-economic development and urbanization. The gross domestic product (GDP) increased by $296.06 \%$, and the urbanization rate increased from $24.00 \%$ to $32.65 \%$, during the same period. The poor transport infrastructures were further improved from 2000 to 2010 , and the total roadways mileage increased from $5368 \mathrm{~km}$ to $19,234 \mathrm{~km}$, with an increase of 13,866 $\mathrm{km}$. Construction land (including residential land and transportation land) increased by $240.30 \mathrm{~km}^{2}$ over the same period. The implementations of reform and opening-up policy in 1995 and the Grain for Green Project in 2000 had profound impacts on land use changes in Zhangjiakou city. The changes in land use intensified. Forestland and construction land increased dramatically, at a rate of $1.32 \%$ and $2.10 \%$, respectively. As a result, grassland and farmland were more likely to convert to forestland in Bashang Plateau and mountainous areas. Construction land expanded by occupying farmland and grassland, and mostly occurred in administrative districts and their surrounding regions. Overall, the land use integrated dynamic degree increased from $2.21 \%$ during $1989-2000$ to $3.96 \%$ during 2000-2010. Considering the socio-economic development and eco-environmental protection, as well as local government policies, four scenarios (land use planning scenario, natural development scenario, ecological-oriented scenario, farmland protection scenario) were designed to simulate land use changes in the study area. With the rapid growth in population and urbanization, and further implementation of the Grain for Green Project, forestland and construction land increased significantly, while farmland and unused land decreased dramatically under the natural development scenario. With the land use planning scenario, land use demands were related to the Land Use Master Plan of Zhangjiakou city (2006-2020), which highlighted farmland protection by strictly controlling the expansion of construction land. Forestland and construction land increased steadily, while the areas of farmland, grassland, water body and unused land were on the decline under this scenario. With the ecological-oriented scenario, there were wide changes in land use in Zhangjiakou city, which were mainly reflected 
in farmland, forestland, grassland and unused land. The conversions of farmland, grassland and unused land to forestland were the principal transformation of land use under this scenario. In addition, policies aimed at the protection of farmland suppressed the increase in land use intensity and the expansion of construction land under the farmland protection scenario.

Landscape metrics can quantify landscape patterns and facilitate the comparison between different land use scenarios. Moreover, metrics can reveal important information about landscape patterns. As a result, landscape metrics have been widely used to analyze landscape patterns of land use changes as well as urban expansion, i.e., metropolitan areas (Jenerette and $\mathrm{Wu}, 2001$; Luck and $\mathrm{Wu}, 2002$; Weng, 2007; He et al., 2011; Wu et al., 2015), desert-oasis areas (Meng et al., 2005; Li et al., 2013; Li et al., 2014), coastal areas (Wu et al., 2013; Fan et al., 2013; Hu and Dong, 2013) and arid inland river basins (Tian et al., 2014; Zhang et al., 2014c). In this study, landscape metrics such as F, LSI, PAFRAC, SHDI, IJI, CONTAG and AI were used to analyze landscape patterns under different scenarios. This revealed that the changes in landscape patterns under different scenarios in 2020 will tend to be less marked as human activities intensify. Fragmentation and irregularity of landscapes decreased from 2010 to 2020 , while concentration and connectivity of landscapes were further improved. Owing to the rapid economic development, and further implementation of the Grain for Green Project, the landscape was characterized by homogeneity and connectivity under the natural development scenario. Land use pattern was more closely related to land use master plan and policies under the land use planning scenario. With increasing urbanization, the landscape became more regular in shape, and landscape diversity increased as well as aggregation under this scenario during 2010-2020. However, in the ecological-oriented scenario and farmland protection scenario, consideration of the responses to human activities, ecological land and farmland protections were the major goals. Fragmentation, heterogeneity and complexity were the most obvious characteristics of landscape changes. Overall, there were also spatial differences in landscape patterns in Zhangjiakou city, which were consistent with the basic pattern of socio-economic conditions and the trend toward changes in future land use pattern.

Owing to the complexity of the land use system, it is necessary to consider and combine different land use processes within a single modeling framework to model land use dynamics (Luo et al., 2010). The CLUE-S model has been recognized as an excellent tool for simulating land use changes (Overmars and Verburg, 2007; Sohl and Claggett, 2007; Pan et al., 2011; Hu et al., 2013; Wang et al., 2014; Zeng et al., 2014). This model has been widely applied to the dynamic studies of land use changes in smaller-scale regions, especially the hot spots of LUCC research in China, such as sandy areas (Zhang et al., 2003), tourism areas (Wang et al., 2014), urban areas (Sheng et al., 2008; Wu et al., 2011; Zhang et al., 2013b; Zheng et al., 2015) and ecologically fragile areas (Li et al., 2011b; Huang et al., 2012; Xu et al., 2013a). In this study, the Markov-CLUE-S model was used to analyze land use changes from both spatial and temporal dimensions. This model obtained the spatial characteristic information of land use changes by analysis tools using GIS. The model parameters were based on the historical land use data from 2000 to 2010 in Zhangiiakou city and were tested by comparing the simulation scenarios of land use with the actual land use in 2010 of the study area. The Kappa value was 0.902 , indicating the reliability of the model simulation. 
The results of land use simulation in 2020 showed the land use alternatives under four different scenarios in the future. The simulation results indicated that land use change was influenced by physical, locational, political and socio-economic factors. Moreover, to a large extent the selected factors can be used to explain land use allocation.

By using multi-temporal remote sensing data and statistical analysis, the CLUE-S model and landscape metrics analysis are combined to simulate the changes in landscape patterns under different scenarios in 2020, which is an efficient method, as proved by certain case studies (Wang et al., 2014; Zhang et al., 2014b; Zeng et al., 2014). This research is a pilot study for applying a simulation model to explain land use dynamics in an urban fringe. The results of combining a Markov model, CLUE-S model and landscape pattern indices (LPIs) suggest that this integrated model has the capacity to reflect the complex changes in land use in Zhangjiakou city, which indicate that the approach can serve as a useful tool for analyzing related driving factors and estimating related effects of the land use dynamic. The integrated model developed in this research considers land use allocation factors including physical, locational and socio-economic attributes, which are comparatively comprehensive. However, the effects of various policy factors and unexpectedness of natural disasters are not considered in the simulation process. Consequently, improving the accuracy of socio-economic factors and reducing the influences caused by the uncertainty of natural disasters and regional policies are likely to become increasingly important in terms of simulating land use changes. Furthermore, it is well known that the land use change process is dynamic and results from the interaction between natural and socio-economic elements at different scales. The simulation of land use change and landscape metrics analysis rely heavily on scale, and results will vary with particle sizes (Røpke, 2005; Hu and Dong, 2013; Wu et al., 2015). In this study, good results were achieved at a scale of $300 \mathrm{~m} \times 300 \mathrm{~m}$ in Zhangjiakou city. A further study could employ regional spatial factors and policy-related factors together in the simulation of further land use change in Zhangjiakou city, which could guide more informed decision making. In addition, multi-scale analysis of land use simulation and landscape pattern changes should be carried out to enhance the reliability of simulation in future research.

\section{Conclusions}

Based on the remote sensing data of Landsat TM images in 1989, 2000 and 2010, using a Logistic regression model, CLUE-S model and landscape metrics, this paper selected Zhangjiakou city - a representative area of the Poverty Belt around Beijing and Tianjin - as an example to simulate land use scenarios driven by different socio-economic and ecological policies and analyzed the landscape pattern dynamic change, aiming to provide useful information for decision-makers and planners to take appropriate land management measures in the study area. The results can be shown as follows:

(1) The land use integrated dynamic degree increased from $2.21 \%$ during $1989-2000$ to $3.96 \%$ during 2000-2010. Comparing the period 1989-2000 with 2000-2010, the rate of farmland, grassland, water body and unused land changed from $0.27 \%, 0.15 \%, 0.88 \%$ and $0.73 \%$ to $0.83 \%, 0.11 \%, 0.94 \%$ and $2.53 \%$, respectively. At the same time, the rate of garden land, forestland, and construction land changed from $0.51 \%, 0.56 \%$ and $1.39 \%$ to $0.01 \%$, $1.32 \%$ and $2.10 \%$, respectively. The administrative districts and their surrounding regions 
were the hot spots in land use changes, where land use changed much faster.

(2) Land use changed significantly throughout 1989-2010. The total area experiencing land use change was $4759.14 \mathrm{~km}^{2}$, accounting for $12.53 \%$ of the study area. Land use transformation was characterized by grassland to forestland, and by farmland to forestland and grassland. During 1989-2000, the conversions of grassland to forestland, and farmland to grassland, constituted the principal transformation of land use. However, throughout 2000-2010 the conversions of farmland and grassland to forestland constituted the principal transformations of land use. The land use changes mostly occurred in Bashang Plateau and river valleys from 1989 to 2010 .

(3) The spatial distribution of land use types could be explained, to a large extent, by the driving factors. The results of land use simulation showed that the CLUE-S model conforms to reality with an accuracy of $90.2 \%$, implying that this model is appropriate for simulating the temporal and spatial variations in the land use of Zhangjiakou city. Under the natural development scenario, the simulation of land use in 2020 indicated significantly rapid reductions in farmland and unused land due to human activities. Additionally, increases in forestland and construction land resulted from the Grain for Green Project and rapid socio-economic development. Under the land use planning scenario, farmland, grassland, water body and unused land shrank significantly, while garden land, forestland and construction land increased. The expansion of construction land had been concentrated in administrative districts and their surrounding regions. Under the ecological-oriented scenario, forestland increased by occupying other landscapes, such as farmland, grassland and unused land. The ecological land is mostly distributed in the river valleys and the mountainous areas. Under the farmland protection scenario, farmland was well protected and stable, and was concentrated in the flat areas. The expansion of construction land was restricted to some extent by farmland in this scenario.

(4) Compared with the actual landscape in 2010, the landscape patterns under the four scenarios in 2020 were found to be less marked. The fragmentation of land use landscapes decreased and landscape shapes became more regular, while the aggregation of landscape patches and connectivity of landscapes increased. There were significant differences among land use patterns under different scenarios. In the land use planning scenario, the landscape pattern tended to be more optimized. Shapes of landscape became more regular and the degree of landscape diversity and aggregation increased. The landscape became less fragmented and heterogeneous under the natural development scenario, as evidenced by the reductions in F and SHDI and the increase in CONTAG. At the same time, under the ecological-oriented scenario and farmland protection scenario, landscapes were characterized by fragmentation and spatial heterogeneity. Spatial differences in landscape patterns also existed in Zhangjiakou city in 2020.

\section{References}

Batisani N, Yarnal B, 2010. Rainfall variability and trends in semi-arid Botswana: Implications for climate change adaptation policy. Applied Geography, 30(4): 483-489.

Braimoh A K, Onishi T, 2007. Geostatistical techniques for incorporating spatial correlation into land use change models. International Journal of Applied Earth Observation and Geoinformation, 9(4): 438-446.

Britz W, Verburg P H, Leip A, 2011. Modeling of land cover and agricultural change in Europe: Combining the 
CLUE and CAPRI-Spat approaches. Agriculture Ecosystems \& Environment, 142(1): 40-50.

Chen H, Wang T, Liang X et al., 2009. Simulation and application of household's LUCC based on a multi-agent system: A case study for Mengcha village of Mizhi county of Shaanxi province. Acta Geographica Sinica, 64(12): 1448-1456. (in Chinese)

Couclelis H, 2005. Where has the future gone? Rethinking the role of integrated land-use models in spatial planning. Environment and Planning A: Environment and Planning, 37(1): 1353-1371.

Dai S, Zhang B, 2013. Land use change scenarios simulation in the middle reaches of the Heihe river basin based on CLUE-S model: A case of Ganzhou District of Zhangye City. Journal of Natural Resources, 28(2): 336-348. (in Chinese)

Deng H, He Z, Chen Y et al., 2013. The land use spatio-temporal pattern simulation in metropolitan fringe of the Sichuan Basin: A case study in Yanjian District, Ziyang City, Sichuan. Scientia Geographica Sinica, 33(12): 1524-1530. (in Chinese)

Ellis E A, Baerenklau K A, Marcos-Martínez R et al., 2010. Land use/land cover change dynamics and drivers in a low-grade marginal coffee growing region of Veracruz, Mexico. Agroforestry Systems, 80(1): 61-84.

Evans T P, Manire A, de Castro F et al., 2001. A dynamic model of household decision-making and parcel level land cover change in the eastern Amazon. Ecological Modelling, 143(1): 95-113.

Fan C, Myint S, 2014. A comparison of spatial autocorrelation indices and landscape metrics in measuring urban landscape fragmentation. Landscape and Urban Planning, 121(1): 117-128.

Fan Q, Yang J, Wu N et al., 2013. Landscape patterns changes and dynamic simulation of coastal tourism town: A case study of Dalian Jinshitan national tourist holiday resort. Scientia Geographica Sinica, 33(12): 1467-1475. (in Chinese)

Feng S, Gao X, Gu J et al., 2013. Land use spatial distribution modeling based on CLUE-S model in the Huangshui River Basin. Acta Ecologica Sinica, 33(3): 985-997. (in Chinese)

Feng Y, Luo G, Zhou D et al., 2010. Effects of land use change on landscape pattern of a typical arid watershed in the recent 50 years: A case study on Manas River Watershed in Xinjiang. Acta Ecologica Sinica, 30(16): 4295-4305. (in Chinese)

Frazier A E, 2014. A new data aggregation technique to improve landscape metric downscaling. Landscape Ecology, 29(7): 1261-1276.

Gong J, Liu Y, Xia B, 2009. Spatial heterogeneity of urban land-cover landscape in Guangzhou from 1990 to 2005. Journal of Geographical Sciences, 19(2): 213-224.

Han H, Yang C, Song J, 2015. Scenario simulation and the prediction of land use and land cover change in Beijing, China. Sustainability, 7(4): 4260-4279.

He D, Jin F, Zhou J, 2011. The changes of land use and landscape pattern based on Logistic-CA-Markov model: A case study of Beijing-Tianjin-Hebei metropolitan region. Scientia Geographica Sinica, 31(8): 903-910. (in Chinese)

$\mathrm{Hu}$ R, Dong S, 2013. Land use dynamics and landscape patterns in Shanghai, Jiangsu and Zhejiang. Journal of Resources and Ecology, 4(2): 141-148. (in Chinese)

Hu Y, Zhang Y, Zheng X, 2013. Simulation of land-use scenarios for Beijing using CLUE-S and Markov composite models. Chinese Geographical Science, 23(1): 92-100.

Huang M, Zhang X, Zhang J et al., 2012. A multi-scale simulation of land use change in Luoyugou Watershed based on CLUE-S model. Resources Science, 34(4): 769-776. (in Chinese)

Jenerette G D, Wu J, 2001. Analysis and simulation of land-use change in the central Arizona Phoenix region, USA. Landscape Ecology, 16(7): 611-626.

Jones K B, Zurlini G, Kienast F et al., 2013. Informing landscape planning and design for sustaining ecosystem services from existing spatial patterns and knowledge. Landscape Ecology, 28(6): 1175-1192.

Li A, Wang A, Liang S et al., 2006. Eco-environmental vulnerability evaluation in mountainous region using remote sensing and GIS: A case study in the upper reaches of Minjiang River, China. Ecological Modelling, 192(1): 175-187.

Li C, Yu F, Liu J et al., 2011a. Research on land use/cover change and its driving force in midstream of the Heihe mainstream basin during the past 20 years. Journal of Natural Resources, 26(3): 353-362. (in Chinese)

Li P, Li X, Liu X, 2001. Macro-analysis on the driving forces of the land-use change in China. Geographical Research, 20(2): 129-138. (in Chinese)

Li S, Zhang X, Li S et al., 2013. Spatial and temporal evolution and mechanism of landscape pattern of oasis of urban in Xinjiang. Economic Geography, 33(12): 161-168. (in Chinese) 
Li X, Ding J, Wang G et al., 2014. Change of LUCC and characteristics of landscape pattern in a typical oasis in Turkmenistan. Journal of Desert Research, 34(1): 260-267. (in Chinese)

Li Y, Deng Q, Zhang D et al., 2011b. Land use and ecosystem service value scenarios simulation in Danjiangkou reservoir area. Transactions of the Chinese Society of Agricultural Engineering, 27(5): 329-335. (in Chinese)

Liang Y, Xu Z, Zhong F, 2011. Land use scenario analyses based on system dynamic model and CLUE-S model at regional scale: A case study of Ganzhou District of Zhangye City. Geographical Research, 30(3): 564-576. (in Chinese)

Liao W, Li L, Wu Y et al., 2011. Land use change and eco-environmental vulnerability evaluation in the Danjiangkou Reservoir Area. Journal of Natural Resources, 26(11): 1879-1889. (in Chinese)

Liu J, Liu M, Zhuang D et al., 2002. Analysis of China's recent change of land use spatial pattern. Science in China: Earth Sciences, 32(12): 1031-1040. (in Chinese)

Locantore N W, Tran L T, O’Neill R V et al., 2004. An overview of data integration methods for regional assessment. Environmental Monitoring and Assessment, 94(1-3): 249-261.

Luck M, Wu J, 2002. A gradient analysis of urban landscape pattern: A case study from the Phoenix metropolitan region, Arizona, USA. Landscape Ecology, 17(4): 327-339.

Luo G, Yin C, Chen X et al., 2010. Combining system dynamic model and CLUE-S model to improve land use scenario analyses at regional scale: A case study of Sangong watershed in Xinjiang, China. Ecological Complexity, 7(2): 198-207.

Luo Y, Yang S, Liu X et al., 2014. Land use change in the reach from Hekouzhen to Tongguan of the Yellow River during 1998-2010. Acta Geographica Sinica, 69(1): 42-53. (in Chinese)

Meng J, Wu X, Li Z, 2005. Land use/cover changes and its landscape ecological effects in the middle-western Hexi Corridor: A case study of Suzhou oases. Acta Ecologica Sinica, 24(11): 2535-2541. (in Chinese)

Ou W, Xiao J, Li W, 2014. Spatial pattern optimization simulation of coastal wetland use based on BP neural network and cellular automata: A case of Dafeng Coastal Wetland. Journal of Natural Resources, 29(5): 744-756. (in Chinese)

Overmars K P, Verburg P H, 2007. Comparison of a deductive and an inductive approach to specify land suitability in a spatially explicit land use model. Land Use Policy, 24(3): 584-599.

Pan Y, Liu Y, Wang J et al., 2011. Non-point pollution control for landscape conservation analysis based on CLUE-S simulations in Miyun County. Acta Ecologica Sinica, 31(2): 529-537. (in Chinese)

Pontius R G, Schneider L C, 2001. Land-cover change model validation by an ROC method for the Ipswich watershed, Massachusetts, USA. Agriculture, Ecosystems \& Environment, 85(1): 239-248.

Røpke I, 2005. Trends in the development of ecological economics from the late 1980s to the early 2000s. Ecological Economics, 55(2): 262-290.

Sheng S, Liu M, Xu C et al., 2008. Application of CLUE-S model in simulating land use changes in Nanjing metropolitan region. Chinese Journal of Ecology, 27(2): 235-239. (in Chinese)

Sohl T L, Claggett P R, 2013. Clarity versus complexity: Land-use modeling as a practical tool for decision-makers. Journal of Environmental Management, 129(16): 235-243.

Su S, Xiao R, Jiang Z et al., 2012. Characterizing landscape pattern and ecosystem service value changes for urbanization impacts at an eco-regional scale. Applied Geography, 34(4): 295-305.

Sun P, Xu Y, Wang S, 2014. Terrain gradient effect analysis of land use change in poverty area around Beijing and Tianjin. Transactions of the Chinese Society of Agricultural Engineering, 30(14): 277-288. (in Chinese)

Tang H, Wu W, Yang P et al., 2009. Recent progresses of land use and land cover change (LUCC) models. Acta Geographica Sinica, 64(4): 457-468. (in Chinese)

Tian X, Wang X, Kadipov K G et al., 2014. Land use/cover dynamic change and landscape pattern analysis in Kayrakkum reservoir area during past 40 years. Transactions of the Chinese Society of Agricultural Engineering, 30(6): 232-241. (in Chinese)

Tian Y, Jim C Y, Wang H, 2014. Assessing the landscape and ecological quality of urban green spaces in a compact city. Landscape and Urban Planning, 121(1): 97-108.

Tian Y, Ren Z, 2012. Land use change simulations in loess hilly areas based on CLUE-S model: A case study in Xianyang loess tableland areas of Shaanxi Province. Progress in Geography, 31(9): 1224-1234. (in Chinese)

Veldkamp A, Lambin E F, 2001. Predicting land-use change. Agriculture, Ecosystems \& Environment, 85(1): 1-6.

Verburg P H, Overmars K P, 2009. Combining top-down and bottom-up dynamics in land use modeling: Exploring the future of abandoned farmlands in Europe with the Dyna-CLUE model. Landscape Ecology, 24(9): 1167-1181. 
Verburg P H, Soepboer W, Veldkamp A et al., 2002. Modeling the spatial dynamics of regional land use: The CLUE-S Model. Environmental Management, 30(3): 391-405.

Verburg P H, Veldkamp A, 2004. Projecting land use transitions at forest fringes in the Philippines at two spatial scales. Landscape Ecology, 19(1): 77-98.

Vitousek P M, Mooney H A, Lubchenco J et al., 1997. Human domination of earth's ecosystems. Science, 277(5325): 494-499.

Wang Q, Meng J, Mao X, 2014. Scenario simulation and landscape pattern assessment of land use change based on neighborhood analysis and auto-logistic model: A case study of Lijiang River Basin. Geographical Research, 33(6): 1073-1084. (in Chinese)

Wang S Y, Liu J S, Ma T B, 2010. Dynamics and changes in spatial patterns of land use in Yellow River Basin, China. Land Use Policy, 27(2): 313-323.

Wang X L, Bao Y H, 1999. Study on the methods of land use dynamic change research. Progress in Geography, 18(1): 81-87. (in Chinese)

Wassenaar T, Gerber P, Verburg P H et al., 2007. Projecting land use changes in the Neotropics: The geography of pasture expansion into forest. Global Environmental Change, 17(1): 86-104.

Weng Y C, 2007. Spatiotemporal changes of landscape pattern in response to urbanization. Landscape and Urban Planning, 81(4): 341-353.

Wu C F, Lin Y P, Chiang L C et al., 2014. Assessing highway's impacts on landscape patterns and ecosystem services: A case study in Puli Township, Taiwan. Landscape and Urban Planning, 128(8): 60-71.

Wu J, Feng Z, Huang L et al., 2011. CLUE-S based scenario prediction on sustainable land use: A case study of suburban district, Yangquan City. Resources Science, 33(9): 1699-1707.

Wu L, Hou X, Xu X et al., 2013. Land use and landscape pattern changes in coastal areas of Shandong province, China. Transactions of the Chinese Society of Agricultural Engineering, 29(5): 207-216. (in Chinese)

$\mathrm{Wu}$ W, Zhao S, Zhu C et al., 2015. A comparative study of urban expansion in Beijing, Tianjin and Shijiazhuang over the past three decades. Landscape and Urban Planning, 134(2): 93-106.

Xu Y, Luo D, Guo H et al., 2013a. Multi-simulation of spatial distribution of land use based on CLUE-S model: A case study of Yuzhong County, Gansu Province. Acta Scientiarum Naturalium Universitatis Pekinensis, 49(3): 523-529. (in Chinese)

Xu Y, Luo D, Peng J, 2011. Land use change and soil erosion in the Maotiao River watershed of Guizhou Province. Journal of Geographical Sciences, 21(6): 1138-1152.

$\mathrm{Xu}$ Y, McNamara P, Wu Y et al., 2013b. An econometric analysis of changes in arable land utilization using multinomial logit model in Pinggu district, Beijing, China. Journal of Environmental Management, 128(15): 324-334.

Yang X, Zheng X Q, Chen R, 2014. A land use change model: Integrating landscape pattern indexes and Markov-CA. Ecological Modelling, 283(13): 1-7.

Zeng Y, Jin W, Wang H et al., 2014. Simulation of land-use changes and landscape ecological assessment in eastern part of Qinghai Plateau. Transactions of the Chinese Society of Agricultural Engineering, 30(4): $185-194$. (in Chinese)

Zhang D, Fu M, Tao J et al., 2013a. Scenario simulation of land use change in mining city based on CLUE-S model. Transactions of the Chinese Society of Agricultural Engineering, 29(12): 246-256. (in Chinese)

Zhang H, Qi Z, Ye X et al., 2013b. Analysis of land use/land cover change, population shift, and their effects on spatiotemporal patterns of urban heat islands in metropolitan Shanghai, China. Applied Geography, 44(5): 121-133.

Zhang L, Yang G, Liu J, 2014a. The dynamic changes and hot spots of land use in Fushun City from1986 to 2012. Scientia Geographica Sinica, 34(2): 185-191. (in Chinese)

Zhang W, Liu M, Qi Y, 2014b. Land-use scenarios simulation based on the CLUE-S model in Kunming. Chinese Journal of Ecology, 33(6): 1655-1662. (in Chinese)

Zhang X, Shi P, Luo J et al., 2014c. The ecological risk assessment of arid inland river basin at the landscape scale: A case study on Shiyang River Basin. Journal of Natural Resources, 29(3): 410-419. (in Chinese)

Zhang Y, Zhao S, Zhang K, 2003. Simulation of changes in spatial pattern of land use in Horqin Desert and its outer area. Journal of Beijing Forestry University, 25(3): 68-73. (in Chinese)

Zheng H W, Shen G Q, Wang H et al., 2015. Simulating land use change in urban renewal areas: A case study in Hong Kong. Habitat International, 46(2): 23-34. 